\title{
NOVELTY ARCHITECTURE AND MATHEMATICS IN AN IRANIAN MOSQUE
}

| Received January, 30th 2019 | Accepted November 26 ${ }^{\text {th }}, 2019$ | Available online June 15th $2020 \mid$ | DOI http://dx. doi. org/10.18860/jia.v6i1.5508 |

\section{Sara Behnamian}

Faculty of Mathematiis

Islamic Azad University

Tehran, Iran

sara.behnamian@srbiau.ac.ir

\section{Saman Behnamian}

Faculty of Engineering

Islamic Azad University

Tehran, Iran

saman.behnamian@gmail.com

\section{Fatemeh Fogh}

Faculty of Mathematics,

K. N. Toosi University of Technology, Iran

ffogh@mail.kntu.ac.ir

\section{Firooz Pashaei}

Department of Mathematics,

Faculty of Basic Sciences,

University of Maragheh,

Iran

f_pashaie@yahoo.com

\section{Malihe Mahin Saran}

Faculty of Architecture and Urban Planning,

Shahid Beheshti University

Teheran, Iran

Msh121281@yahoo.com

\section{INTRODUCTION}

The architecture design of mosques has local as well as global significance, representing religious, economic, and aesthetic dimensions of Muslim society. In other words, the typology of sacred architecture is complex and reflects cultural patterns. Therefore, Muslim architects adapted their structural, spatial, and decorative designs accordingly. For instance, the fact that there should be domes and minarets attained full reflection of the obedience to God, which became the main part of Muslim religious architecture. The dualism of domes and minarets achieved a perfect expression of the submission to Allah, which became a central element of Muslim religious architecture [1]. The most prevalent shapes of the dome are spherical-shaped. In the early era, they were smaller and built on the passing earlier than the Mihrab, as seen in Qairwan (170-675), Umayyad Mosque in Damascus (705-707), and Cordoba (756-796) [2].

The most common and oldest forms of the dome are the semi-circular. Concerning the size, the earliest domes were small and often erected on the crossing before the Mihrab, as seen in Qairawan (670-675), Umayyad Mosque in Damascus (705-707), and Cordoba (756-796). The scale of domes increased, as well as their structures, varied [3].

In recent decades, mosque design has experienced some developments that find some novelties in mosque architecture [4]. One of these novelties is in a dome form that changes during time. Architects have many tools to create this new design. One of the tools is from mathematics science called a fractal. This study aims to analyze some new mosque designs using the fractal method. This study may have benefits for other architects to use fractal for creating mosque design in the future.

\section{METHODS}

In this paper, the author observed the architecture of Quds mosque from a mathematical standpoint. The 
mosque is located in Saadat Abad, Tehran. It is an example of a dome-less and modern mosque. The architects may be inspired by the Shah Faisal mosque in Islam Abad, Pakistan. However, this is not declared by the architects.

A mathematical term which is commonly used for identifying similarities is called "fractal." Fractal is typically described as exhibiting self-similarity. In other words, the patterns appear to be identical or almost identical observed from the top or any distances, whether close or far. The part looks like the whole, and the whole looks like a part.

The root of the word fractal comes from the Latin word fractus that means broken or irregular. A fractal is a mathematical set that typically displays self-similar patterns. It originally referred to as fractional dimensions and irregular surfaces [5]. Fractal geometry is a new branch of experiential mathematics that recognizes objects in the real or nature are not purely square, triangular, circular, spherical, cylindrical, and other fixed geometrical form. New tools for geometry have been introduced to describe objects of extreme complexity, such as clouds, ferns, snowflakes, mountain ranges, stock-market fluctuations, human circulation, and the nervous system. They have been used in art before the term fractal invented in the 1970s [6]. Fractals are also seen in Architecture. It is very functional in the design of Iranian architecture. From the perspective of the fractals, geometry always plays an important role in constructions [7].

\section{RESEARCH OBJECT}

\section{SHAH FAISAL DOME-LESS MOSQUE}

There are small number of mosques examples that lack any or all of these architectural features, but they still retain traditional Muslim values. As an example, we can see the Shah Faisal Mosque of Pakistan. This modern mosque does not have any dome.

Usually, the architecture of the mosque has three remarkable features: domes, arches, and minarets. The architectural style has been instrumental in expressing thought. Each civilization developed its architectural style that developed its identity. Dome is recognized as one of the most important elements in the architecture of the mosque, specifically and Islamic architecture in general [8].

The concept of domes among Muslim architects has become one of the most significant elements in Islamic architecture because of its symbolic inspiration [9][10]. Then, with the advent of new technologies and innovative techniques, which is eliminating structural constraints constantly, the architectural form changed. Shah Faisal mosque is a distinguished example of that (Figure 1). However, the Faisal Mosque architecture is modern, unique and lacks both the traditional dome and the arches of most other mosques all over the world [8]

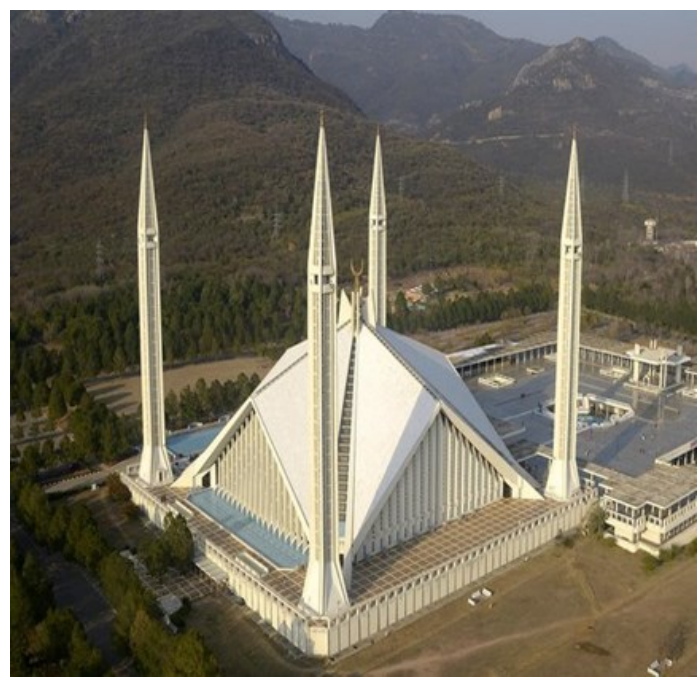

Figure 1. Shah Faisal Mosque

\section{QUDS MOSQUE IN TEHRAN}

The Quds mosque in Tehran is dome-less and resembles a the Fasial mosque. In other words, the architecture of the Quds mosque has been inspired by the Faisal Mosque. It is an exquisite architectural feat with a modern outlook that came under a lot of criticism for abandoning the traditional symbols of Islamic architecture. But after a while, it became an acceptable architecture for a mosque.

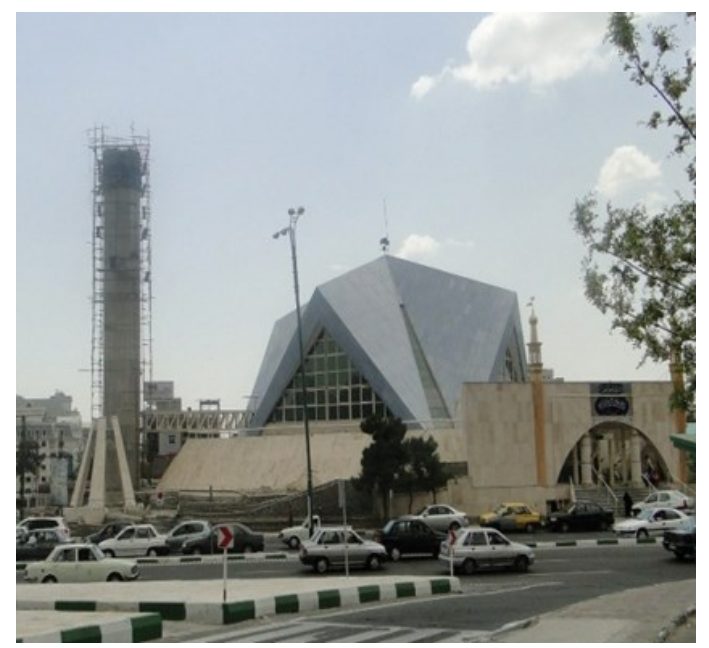

Figure 2. Quds Mosque

As figures 2 shows, it is a picturesque architecture with a modern outlook. But at first, no one could accept it as a mosque. In other words, it was perceived as a contradiction between this and traditional symbols of mosques. 


\section{DISCUSSION}

\section{SORTS OF NOVELTY ARCHITECTURE}

There are three types of architectural designs classified according to the novelty architecture:

- A programmatic architecture where buildings are programmed to use an animal, food, or people shapes to mimic and propagate the functions of special buildings.

- Giant sculptures which were mainly used to attract customers, especially in souvenir shops. These sculptures are great displays of ordinary objects such as guitars, baskets, even a huge fish.

- Styling buildings After famous landmarks are used to duplicate existing constructions or buildings as a matching or emulation of an existing building to create a sense of such areas. Amusement parks, casinos, and restaurants.

According to the categories, as the main structure of these two mosques is approximately the same. It can be claimed that the Quds is a novelty architecture type three. It was built after the famous mosque of Shah Faisal as an imitation of an existing mosque to create the feel of a place for worshiping.

Although Quds mosque was made to look like Shah Faisal, there is a distinct difference between the two. For instance, Shah Faisal has four minarets, whereas Quds does not have any. Shah Faisal is more exquisite than Quds, but the point is that Quds is still under construction (As illustrate). Also, they are different in their surroundings:

- Shah Faisal mosque is located in a huge open space which offers a spectacular perspective of the whole building. In contrast, not only is Quds mosque built in a small site, and no landscape has been designed for it, but also located at the corner of a very crowded junction has disturbed its view (figure 3 ).

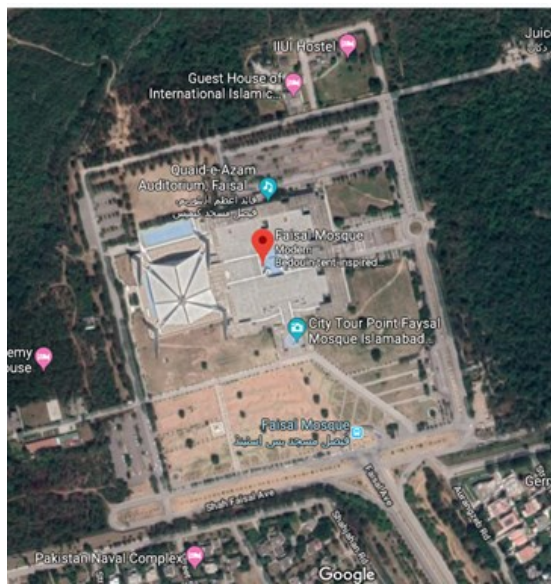

Figure 3. Shah Faisal mosque's site

- In terms of functions, Shah Faisal and its neighboring buildings support one another. There is a library, lecture hall, and museum whose functions are similar to that of the mosque. The Quds, however, is surrounded by a fire station in the South and a carwash in the West. It has furthermore compounded the visual anarchy and confusion of the site (figure 4).

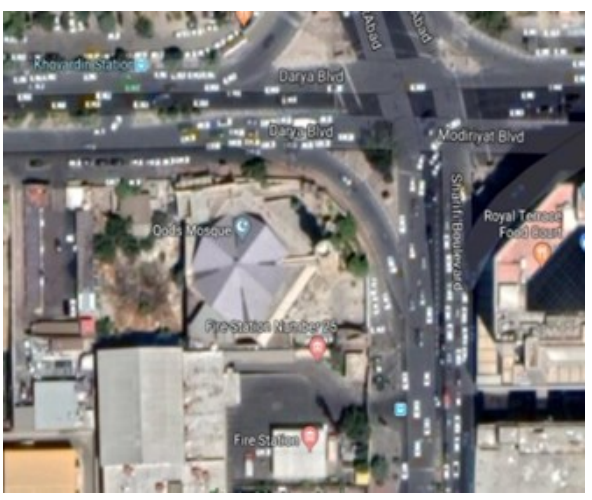

Figure 4. Quds mosque's site

\section{RESCALING}

Enhancing experienced templates to make them compatible in different sites according to requested space has given rise to developed architecture, hence advanced urban design. Zavare mosque in Iran is an example of the first pattern of a four-porch mosque and Isfahan mosque, again in Iran, which its pattern transformed into four porches mosque was inspired by Zavare.

Throughout architectural history, rescaling prominent architectural patterns and their spatial organization, within the same or similar culture, in particular, has been common. Retrofitting and betterment of well -known patterns for fitting them in various sites according to required spaces has resulted in the development of architecture and an improvement in advanced urban design. For example, the Zavareh mosque is the first mosque with a four-porch pattern in Iran [11] [12], and was the source of inspiration for Isfahan mosque, whose pattern was translated into four-porch mosques (figure 5,6).

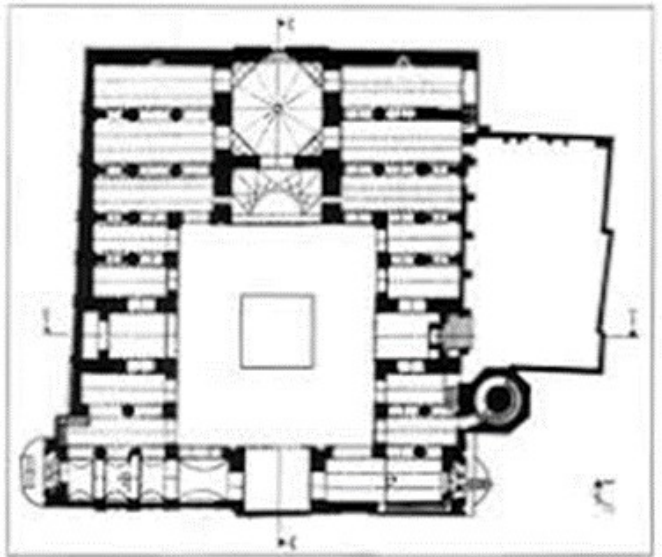

Figure 5. Zavare mosque in Iran as the first pattern of four porches mosque 


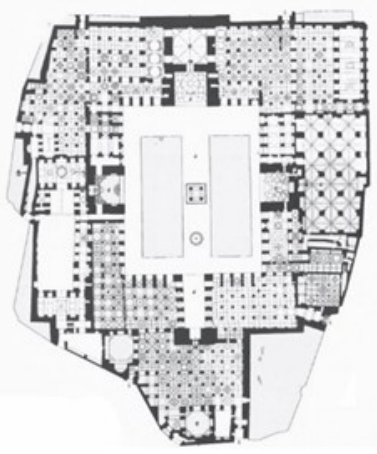

Figure 6. Isfahan mosque in Iran which is an example of a four porches mosque

Overlooking the context and site's circumstances in Quds mosque reveals that it has led to unsatisfactory results. Quds mosque by reducing dimensions of Shah Faisal mosque is not translated into a suitable project in its context.

\section{MATHEMATICAL PROPERTIES OF QUDS FRACTAL}

In mathematics, a self-same object is identically or nearly to a piece of itself (i.e., the whole has the identical configuration as one or more of the parts). Selfsimilarity is a typical exclusivity of artificial fractals. Scale invariance is an exact form of selfsimilarity where at each magnification, there is a smaller piece than the object that resembles the whole. A side of the Koch snowflake is both symmetrical and scale-invariant; It can be magnified three times continuously without deformation. The famous non-trivial similarity in fractals is distinguished by their fine structure or detail on arbitrary tiny scales [13].

Fractals, for example, the Sierpinski triangle and the Koch snowflake, can be produced by a sagely and exact process: a basic form is used as the starting point, modifications are applied, and the resulting object is transformed with the same (figure 7). Of course, fractals, such as the Mandelbrot set, involve more complex mathematics (figure 8) [6].
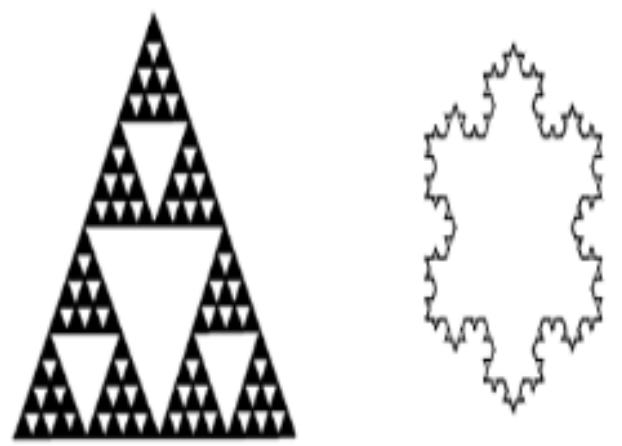

Figure 7. The Sierpinski triangle and the Koch snowflake

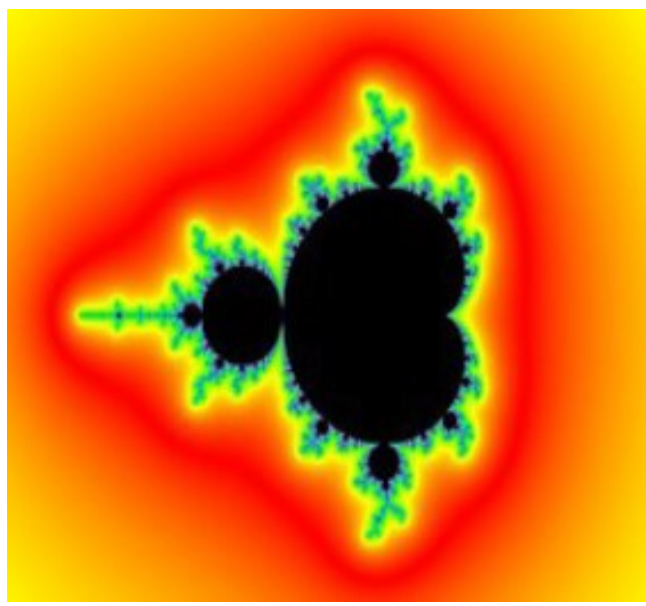

Figure 8. The Mandelbrot set

\section{CONGRUENCY}

Two geometrical stuff are called similar if their figures are similar, or one has the same form as the mirror image of the other. More accurately, one can be gained from the other by uniformly scaling (enlarging or reducing), with more translations, rotation, and reflection. It means that either object can be rescaled, repositioned, and reflection, to coincide precisely with the other object. If two things are similar, each is congruent with the result of a specific uniform scaling of the other [14]. The system of geometric design in Islamic architecture mainly commences from a square or a circle [15]. The models are obtained from two primary geometric theories; rotating a square or squaring the circle. Mathematicians have presented studies in mathematics and geometry extracted from natural organisms [16][17].

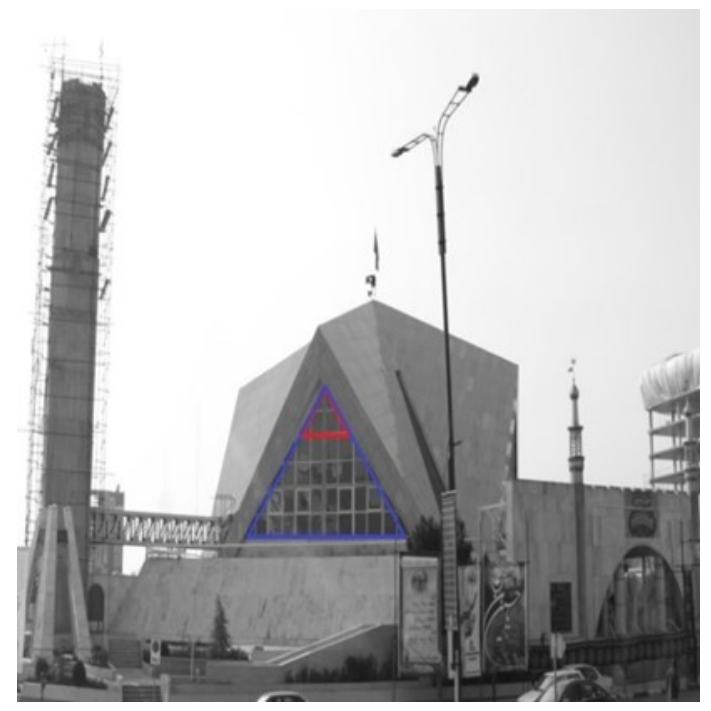

Figure 9. Congruent Triangles

A visual analysis (versus dimensional analysis) of the architecture is a consideration of the building to identify their self-similar parts [18]. There are lots of

10 | Journal of Islamic Architecture, 6(1) June 2020 
congruent triangles by a visual observation and analysis, so it has fractal.

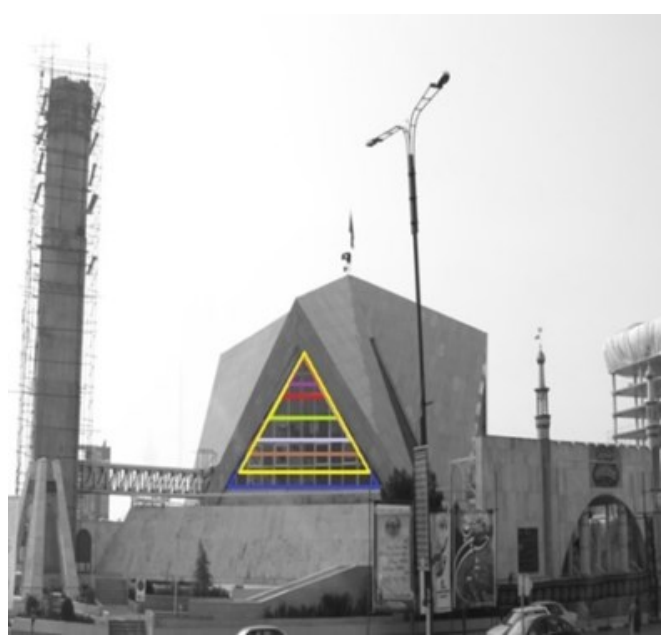

Figure 10. Congruent Triangles, Self-similar Fractal

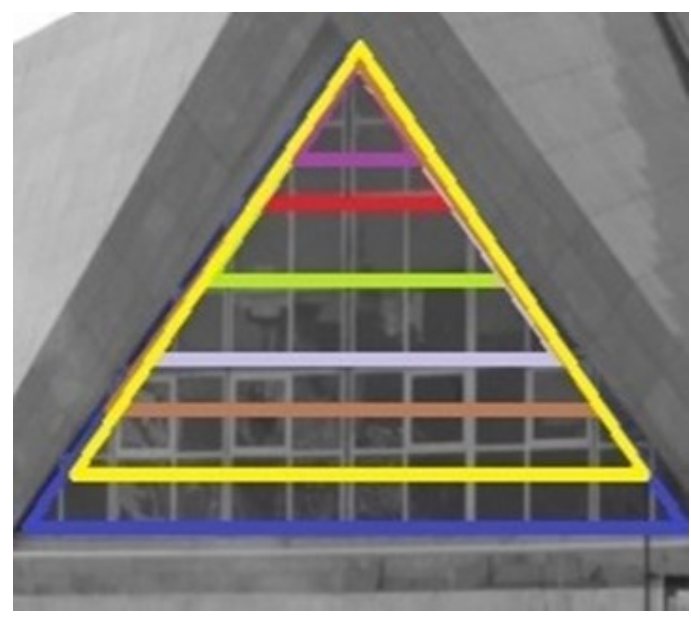

Figure 11. Congruent Triangles, Self-similar Fractal

As Figure 9, 10, and 11 illustrate, there are a lot of congruent triangles. The blue triangle is congruent to the yellow one, it is also congruent to the red one, etc. Hence, there are lots of congruent triangles in this window of the mosque. As it is mentioned above, these congruent triangles make fractals.

\section{CONCLUSION}

The architecture of mosques is being changed somehow as the architecture of our buildings. For example, Quds mosque, which its architecture was a controversial issue someday, but as times passed, it became acceptable, and recently, many people go there for praying and worshipping Allah.

Quds mosque can be described as one of example of novelty architecture that can be analyzed mathematically. Quds mosque used fractal principles; self similarity and congruancy. Those are applied in the roof form by using triangle form in each side.

\section{REFERENCES}

[1] D. Kuban, "The Style of Sinan's Domed Structures," Muqarnas Online, vol. 4, no. 1, pp. 72-97, 1986.

[2] S. T. Al-Hassani and S. Brentjes, "1001 Inventions: The Enduring Legacy of Muslim Civilization," Aestimatio: Critical Reviews in the History of Science, vol. 10, pp. 119-153, 2013.

[3] R. Saoud and S. Al-Hassani, A Review on Mosque Architecture. Manchester: FSTC, 2002.

[4] Y. Ardhiati, "The New Architecture of Mosque Design to Express the Modernity of Moslems," Global Advanced Research Journal of Arts and Humanities (GARJAH), vol. 2, no. 4, pp. 75-78, 2013.

[5] S. Behnamian, S. Behnamian, and F. Fogh, "Observing Self-Similar Fractal in a Famous Iranian Song and a Famous Iranian Architecture," in The 2nd National Conference on Mathematics and Statistics Modeling in Applied Studies, 2018.

[6] D. Kormann, "Fractal music," Plus Magazine, 2010. [Online]. Available: https:// plus.maths.org/content/os/issue55/features/ kormann/index. [Accessed: 01-Dec-2018].

[7] H. Pudine, "A Study on Dimensions of Fractal Geometry in Iranian Architecture," Quarterly of Urban Management, vol. 42, no. 15, pp. 257-267, 2015.

[8] R. Jamil, "Role of a Dome-Less Mosque in Conserving the Religious and Traditional Values of Muslims: An Innovative Architecture of Shah Faisal Mosque, Islamabad," International Journal of Architecture, Engineering and Construction, vol. 6, no. 2, pp. 40-45, 2017.

[9] M. Tarrad and M. Matrouk, "The dome in Islamic architecture and the contemporary orientations to the design of Mosques' domes," in Proceedings of the International Congress: Domes In The World, 2012.

[10] A. A. Elkhateeb, "Domes in the islamic architecture of Cairo city: a mathematical approach," Architecture, Systems Research and Computational Sciences, vol. 14, no. 1, pp. 151-176, 2012.

[11] H. Motedaien, "Four-Porch Mosques," Honar Ha Ye Ziba, vol. 6, pp. 84-89, 2000.

[12] A. Kamel, Umayyads and Their Architectural Archeology in the Levant, Iraq, Hejaz, Yemen, Egypt and Africa. Cairo: Dar Alafaq Alearabit, 2002.

[13] B. Mandelbrot, "How Long Is the Coast of Britain? Statistical Self-Similarity and Fractional Dimension," JSTOR, vol. 156, no. 3775, pp. 636638, 1967.

[14] S. Yu and Y. Geng, "Influence Analysis of Underground Excavation on the Adjacent Buildings and Surrounding Soil Based on Scale Model Test," Advances in Civil Engineering, vol. 2019, pp. 1-15, 2019.

[15] E. Broug, Islamic Geometric Patterns. London: 
Thames \& Hudson Lt, 2008.

[16] M. Ben-Hamouche, "Fractal Geometry in Muslim Cities:How Succession Law Shaped Morphology," Nexus Network Journal, vol. 13, no. 1, pp. 235-251, 2011.

[17] M. Abdelsalam and M. Ibrahim, "Fractal Dimension of Islamic Architecture: The case of the Mameluke Madrasas: Al-Sultan Hassan Mad- rasa," Journal of Science, vol. 32, no. 1, pp. 2737, 2019.

[18] M. Y. Shishin and K. J. A. Ismail, "A Method of Compositional Fractal Analysis and its Application in Islamic Architectural Ensembles," International Electronic Journal of Mathematics Education, vol. 11, no. 5, pp. 1087-1100, 2016. 